\title{
The Integrated Design Mode of Government-Leading Major Projects
}

\author{
Ma Jian, Liu Jian, Zhou Xingyu, Zhao Qingdong \\ No. 89 Huangpu S Rd, Hexi, Tianjin, China, A-D-3003 \\ lioncats@qq.com, tjxmvision@126.com
}

Keywords: Government-leading; Major Project; Integration; Design mode.

\begin{abstract}
This paper, by analyzing the government-leading major projects and features of the traditional design mode, explains their conflicts and the reason behind. Based on its summary of the successful experience of government-leading major projects, it proposes an integrated design mode, which centers on optimizing the design process, controlling the design nodes and compiling design guidelines and explains its significance in urban construction.
\end{abstract}

\section{The Conflicts of Government-Leading Major Projects and the Traditional Design Mode}

\section{Features of Government-Leading Major Projects}

Since the reform and opening up, China has undergone great development with rapid expansion of urbanization and fast developed urban construction. The speed of China's urban construction reached its historical high during the "Tenth Five-Year Plan". In recent years, with the increase of government investment, supervision and management, a number of government-leading major projects have emerged (hereinafter referred to as "governmental projects"), whose impact is significant to urban construction and social development.

Some common features have been concluded by extracting and comparing the pivotal factors of governmental projects, which are mainly demonstrated in the following three aspects:

\section{High requirements.}

The general market-leading projects led by developers normally aims at acquiring economic benefits. The planning and design requirements of this kind seek to maximize the project's benefits with the prerequisite of fulfilling the functional qualities and standards.

However, governmental projects differ from the former in that they are highly related to people's livelihood and urban construction, serving to be a model case of urban development and a force to promote it. The requirements of these projects are quite different from that of the market-leading ones, because it prioritizes the social benefits which focus on fulfilling social demands and resolving social conflicts. In addition, it is supposed to make economic balance via reasonable project solution, promoting the periphery regional economic value and urban, social development.

Therefore, governmental projects have higher demand on planning and design. It requires architects to give due consideration to social problems and conflicts while fulfilling the functional qualities and to propose design solutions to maximize the social benefits.

\section{Strict schedule.}

The construction cycle of general market-leading projects normally takes three to five years whose prophase planning and design takes one to two years and construction phase three to four years. Due to the social pressure and political demands, the governmental projects, on the other hand, often has a compact schedule for construction cycle within three years, with less than one year for prophase planning and design. During this phase, architects are required to complete the prophase planning, comprehensive planning, urban design, detailed regulations, architectural design and municipal 
engineering design etc., and they have to demonstrate all these in the working plans. Therefore, the schedule is very strict for all design works to be done within one year.

\section{Multiple participants.}

The scale of the general market-leading projects tends to be limited due to the capacity of developers; thus, it often has only one managing unit or one development and construction unit. However, the governmental projects tend to be large with multiple participants in the play. Besides, in order to catch up with the time, the project is usually divided into several sub-projects and conducted by a number of deign units simultaneously. Take Tianjin Haihe Education Park Project for example, the managing unit is Haihe Education Park Command Department, the proprietor units are the seven colleges moved to the Park in the first phase and the construction unit is Tianjin Bei Yang Yuan Company. In addition, each college has its own architectural design unit and landscape design unit, plus other planning, municipal administrative design units, which amount to dozens of participants.

\section{The Traditional Planning and Design Mode}

The traditional planning and design normally follows the following steps: comprehensive planning - detailed planning - municipal administrative planning - architectural planning landscape planning (see Figure 1).

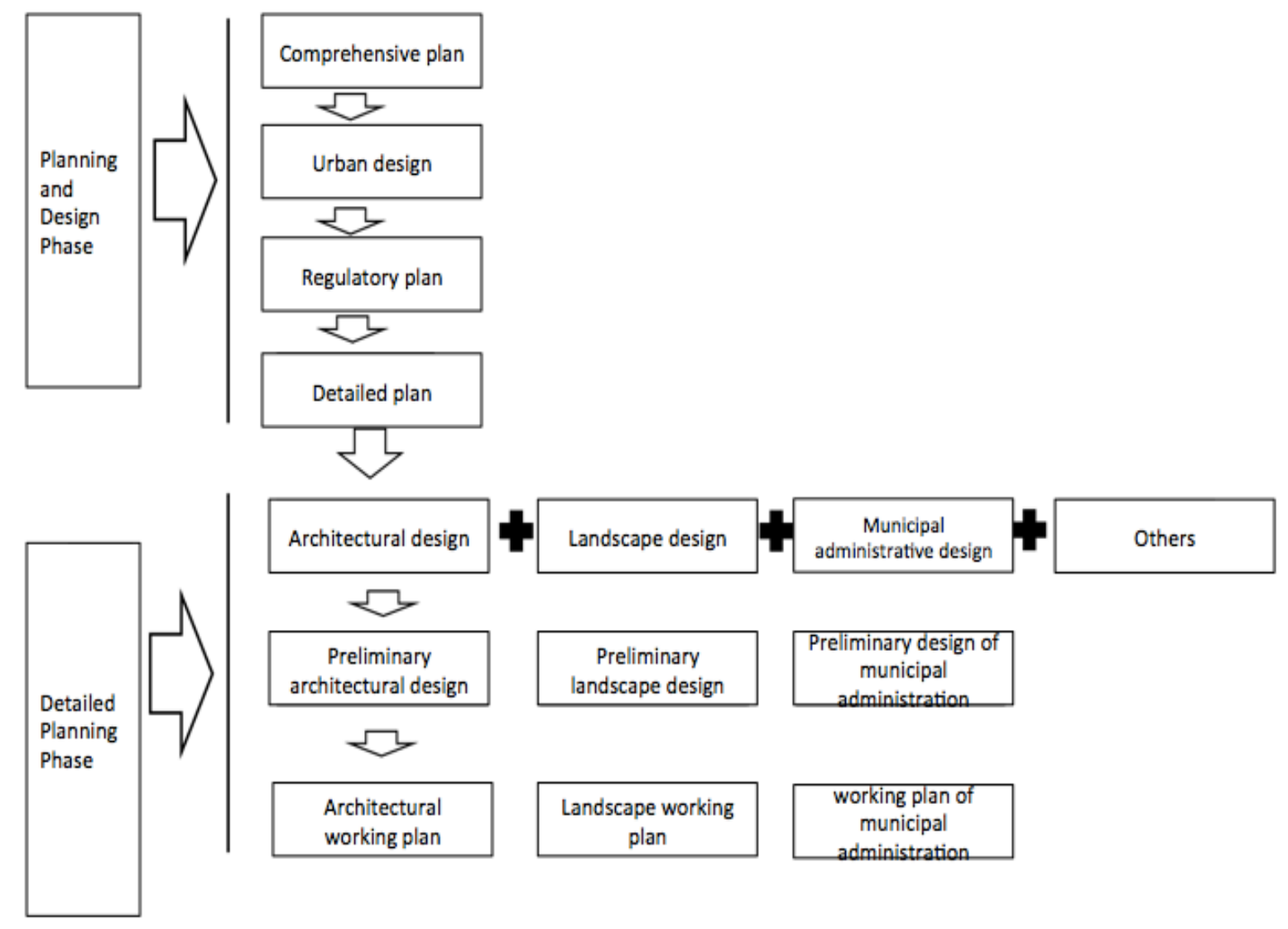

Figure1 The Traditional Design Flow Chart

First, the conceptual urban design is entrusted to the planning and design unit by the government or the developer. After the review and approval of the conceptual solution, follows the compilation of 
the comprehensive plans or regulatory detailed plans according to the project level; then comes procedures of land bid invitation, auction and listing etc. When the developer acquires the land use rights and determines the project content, the planning and design unit will compile a constructive-detailed plan, the municipal administrative design unit will compile a civic design and file a report. Then, the developer will divide the project into several sub-projects according to the scale and invite bids from architectural design institutes. The one that get the bid will design the comprehensive plan and the architectural solution of each area and complete the extended preliminary design with the help of the municipal engineering professionals, finally moving to the construction phase. When the architectural design is completed, the developer will invite bid from landscape design unites and accomplish the landscape design and the working plan with similar methods.

\section{Conflicts}

By analyzing the project, the paper finds that conflicts arise from the application of the traditional design mode to governmental projects, which are shown in three aspects:

\section{Efficiency.}

When planning, the architecture and the municipal administration are working independently; thus, the time of coordination among these participants could be demanding. Besides, some detailed problems often result in reworking of the work from the previous phase, which will surely increase the time and workload of designing. However, large-scale projects usually have high demand on efficiency, requiring shorter working period than the average ones. Consequently, this conflict will cause the design fall behind the schedule and delay the construction.

\section{Design capabilities.}

In the traditional mode, each participant is chosen separately without any unified, complete supervision and selection, which inevitably let some low-level design units into the project. According to the Cask Theory, the failure of low-level design unit to accomplish the relevant work will lower the overall design capability, thus affects the entire project capability and project quality.

\section{The idea of design.}

In the governmental projects, despite of the variety of professions involved, the tenet and ideal should be unanimous. However, in the traditional mode, different professionals work independently, lacking communication, which often results in inconsistency among planning, architecture and construction. The project produced is often quite different from the original plan, for example, Chinese style architecture with European style landscape. This will eventually affects the overall style and fails to satisfy the requirements from the government.

Based on the analysis of these conflicts, the paper seeks to explore a new design mode to solve the problem and ensure the design to be done successfully.

\section{The Integrated Design Mode}

The integrated design mode reorganizes and integrates the original planning and design. It takes the planning and design unit as the lead, optimizes the design process and makes overall plan of the design work. It regulates the design nodes to improve quality and compile design guidelines to unify the design ideas.

\section{Optimizing the Design Mode}


The integrated design mode is essentially different from the traditional mode in terms of design process. The latter follows the administrative examination and approval; however, the integrated design mode takes different participants of the project as a whole and makes uniform arrangement of the design work.

First, the integrated mode will invite professionals from architecture, landscape and municipal administration to the team in advance. When the conceptual plan is made, it will allow the professionals to fully understand the overall conception and design philosophy. Meanwhile, the professionals can also offer their preliminary advices and discern possible problems hidden in the plan in advance, so as to come up with solutions to avoid reworking and speed up the process.

Second, the planning unit will control the design of the entire process. By making the urban design guidelines, the planning unit put forward its requirements for design to architecture, landscape and municipal administration etc. The design solutions made after the guidelines by different professional design units will be examined and approved by the planning unit so as to control their development to be line with the overall design philosophy.

Finally, the integrated mode will regulate the design process. When the urban design solution is made, regulatory planning, detailed planning and architectural solution design will start synchronously. The regulatory plan will decide on the land area, construction index and supporting facilities according to the urban design. Based on the design conditions made after the regulatory plan and the assignment of Party A, the architectural design unit, together with the planning unit, will elaborate on the detailed design solutions to determine the design solutions for plane layout, road traffic, open space, architectural image, and facade styles. When these design solutions are approved, the planning unit will go on with the detailed planning solutions; the architectural units will finish the single solution and move to working plan design. The landscape design works the same as this.

The integrated design mode has turned away from the traditional design mode of assembly-line style to a parallel one with works to be done by multiple professions synchronously. Thus, it increases the communication and interaction between different design sections, reduces the reworking possibility and dramatically shortens the time for design.

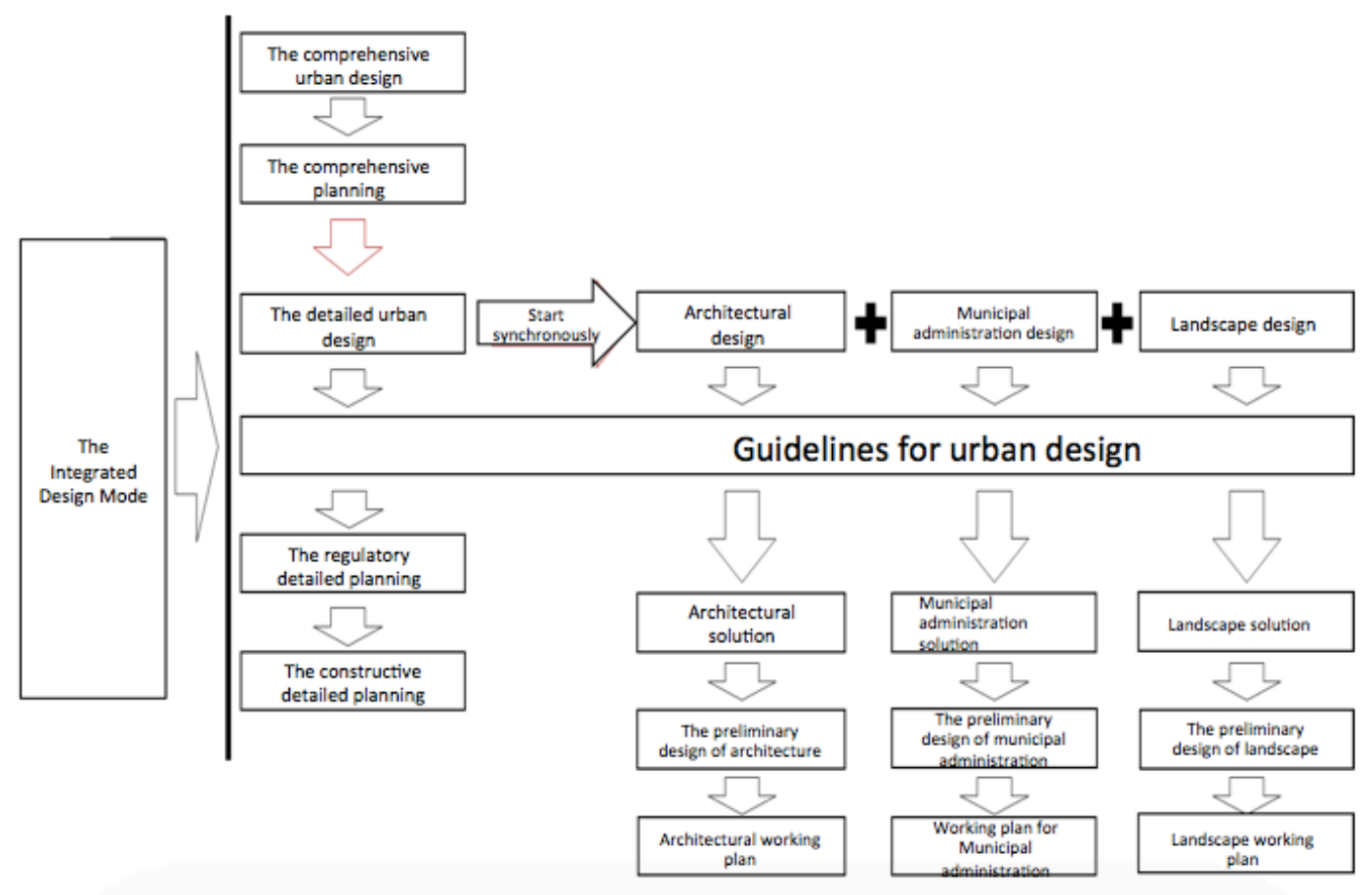

Figure 2 The Flowchart of the Integrated Design Mode

\section{The Control of the Design Nodes}


In the integrated design mode, several nodes are significant to the development and working tempo of a project.

First, the comprehensive urban design. The comprehensive urban design includes project orientation, functional layout, overall scale, the comprehensive conception of the municipal road system, the comprehensive conception of the ecological system etc. The examination and approval of the comprehensive urban design is to ensure its future development and it is important to project initiation.

Second, the detailed urban design. The urban design in this process will elaborate on the detailed planning to decide the detailed solution for the municipal road system. Meanwhile, the architectural professionals will design images for single architecture. The specific images of the design solutions will be shown to Party A in this stage and the design style and method of the project will be determined so as to be prepared to move to the construction phase.

Third, the landscape planning and design. In this phase, the landscape professionals officially begin the comprehensive landscape solution design. Based on the planning and architectural design, the landscape solution accomplishes the environmental design and betters some design conceptions that planning and architectural design fail to realize, so as to improve the overall design.

As long as these three design nodes are under control, the development of the design solution will not deviate from the plan; the demands of Party A will be clearly understood; and time and resource allocation will be in check.

\section{The Compilation of the Design Guideline}

The design guideline is the fruit of urban design, a significant part of the integrated mode. The guideline includes the planning guideline, architectural guideline, landscape guideline, municipal guideline etc. These guidelines are the elaboration of the deign philosophy. They use the conceptions and principles of the design solution to compile the regulatory documents and drawings of different systems, so as to ensure that the next professionals will understand the idea of the original solution and to keep in line with the overall design style.

\section{The Significance of the Integrated Design Mode}

The integrated design mode targets the governmental projects. By adopting this mode, it can make the planning and design adapted to the working condition of governmental projects, meeting the requirements and resolve conflicts at work. It can also mobilize design units to best exhibit their merits and divide their work reasonably to improve the design.

Allowing the planning unit to be responsible for the design work can ensure the design philosophy is carried out thoroughly, truly showing the importance and guidance of planning in urban development and construction. Meanwhile, by controlling the workflow and nodes, it ensures the planning philosophy is carried out in every design section, even the construction; thus, it reduces the conflicts among different design units, improves the project quality and ensures the construction.

In Tianjin, the integrated design mode has been promoted and applied to many governmental projects, such as the planning of Beitang District of Binhai New Area, the protective and exploitative planning of Tai An Road historical district, the planning of Jiefang South Road etc. This mode is significant to the construction of major projects in Tianjin.

\section{Conclusion}

With the development of China's urbanization, the importance placed on the research of planning and design mode will be increased. It is necessary to propose innovative design mode based on the comprehensive design work of the major construction projects, so as to ensure that the planning and design can meet the requirements of governmental projects and keep abreast with the development of the city. 


\section{References}

[1] The Planning of Tianjin Hua Ming town of Dong Li District

[2] The Planning of Tianjin Haihe Education Park

[3] The Planning of Tianjin Beitang

[4] The Protective and Exploitative Planning of Tai An Road Historical District

[5] Tianjin Urban Planning Management Technical Regulations 